Bulgarian Academy of Sciences. Space Research and Technology Institute.

Aerospace Research in Bulgaria. 33, 2021, Sofia

DOI: https://doi.org/10.3897/arb.v33.e11

\title{
APPLYING THE CONSTANT STRENGTH DOUBLET METHOD TO RESOLVE A STEADY FLOW AROUND AN AIRFOIL
}

\author{
Konstantin Metodiev \\ Space Research and Technology Institute - Bulgarian Academy of Sciences \\ e-mail: komet@space.bas.bg
}

Key words: Panel Method, Airfoil, Lower Upper Decomposition, Tiny C, Mugin

\begin{abstract}
In the paper hereby, a numerical (panel) method is applied to analyze steady twodimensional flow of ideal gas around an airfoil. Initially, the airfoil is divided into a finite number of panels. Then the panels are replaced by doublets with constant strength. In addition, a wake panel is added to fulfill Kutta condition at the airfoil trailing edge.

In order to implement this, a numerical realization is developed and built by means of Tiny $C$ Compiler. To work out a solution to the linear non-homogeneous algebraic system, direct schemes for lower-upper factorization / decomposition of matrix of coefficients were applied, namely Crout, Doolittle, and Cholesky.

The obtained results are validated against exact solution and shown for various values of angle of attack and Reynolds number.
\end{abstract}

\section{Introduction}

For couple of years, the personnel of Department of Aerospace Control Systems have been utilizing the Chinese Mugin-3 unmanned aerial vehicle, [1], Fig. 1. Unfortunately, the airplane is deficient in some important flying and maneuvering characteristics which are supposed to have been computed by the manufacturer. By reason of making up for the missing data, the proposed study aims at retrieving aerodynamic characteristics of Mugin-3M UAV wing airfoil, such as the static pressure coefficient. The initial data are airfoil geometry, Reynolds number, and angle of attack. The airfoil geometry was politely submitted to the author by a Mugin Ltd. correspondence clerk.

The proposed study follows a computational algorithm thoroughly described by Katz and Plotkin in their famous textbook [2] and implemented further by a computational code developed in ForTran. In order that infringement of proprietary rights can be avoided, alternative source code has been developed in 
C sticking rigidly to the same algorithm of computing the induced velocities and proposing an alternative for working out a solution to the linear algebraic system.

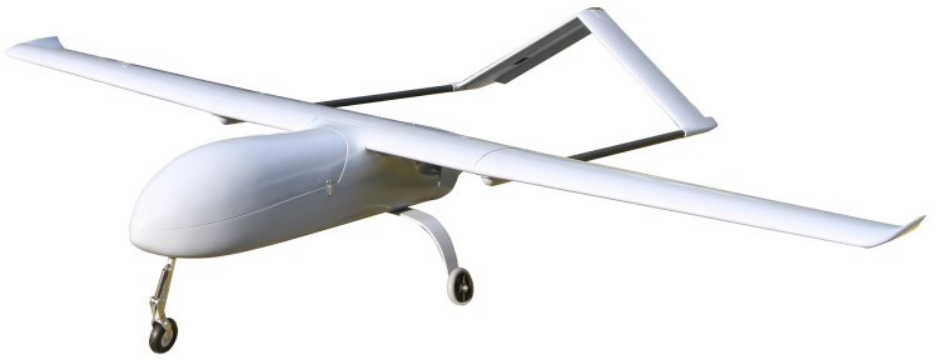

Fig. 1. Mugin-3 $3220 \mathrm{~mm}$ UAV V-tail platform frame kit, [1]

\section{Method}

A few major stages during solution workflow are outlined below.

\section{Discretization of geometry}

At first, the airfoil is divided into finite number of panels in accordance with what is depicted in Fig. 2. A circle is drawn with center placed at the chord middle and radii of half a chord. Copies of the radii are evenly distributed in a circular pattern around the center point so as to obtain the so-called polar array, [3]. Each copy of the radii intersects the circle at a point which is further connected to the mirror one across the abscissa by a vertical line (dash). Wherever a vertical line intersects the airfoil contour, the panel end point is defined. This method makes the panel end points close up (concentrate) in the vicinity of both leading and trailing edges where the flow parameters change intensively.

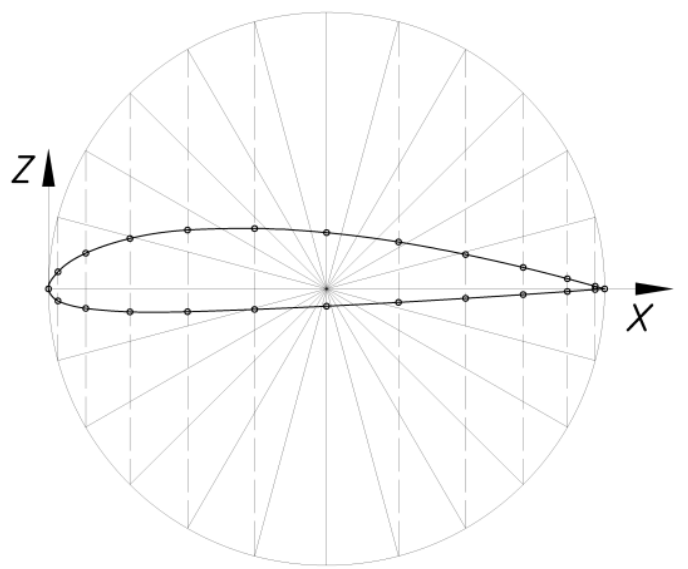

Fig. 2. Dividing an airfoil into panels 


\section{Computation of influence coefficients}

A boundary condition imposed on the problem under consideration implies that normal flow component is not allowed through the airfoil contour. The normal velocity component at each collocation point $C_{i}$, Fig. 3 , could be divided into a self-induced and a free-stream part, [2]. The former quantity is computed by

$$
\begin{aligned}
& u_{p}=\frac{1}{2 \pi}\left[\frac{z}{\left(x-x_{1}\right)^{2}+z^{2}}-\frac{z}{\left(x-x_{2}\right)^{2}+z^{2}}\right] \\
& v_{p}=\frac{-1}{2 \pi}\left[\frac{x-x_{1}}{\left(x-x_{1}\right)^{2}+z^{2}}-\frac{x-x_{2}}{\left(x-x_{2}\right)^{2}+z^{2}}\right]
\end{aligned}
$$

where $u_{p}$ and $v_{p}$ denote induced velocities computed in a local (panel) coordinate system, $\mathrm{x}_{1}, \mathrm{x}_{2}$ denote panel end abscissas $\left(\mathrm{z}_{1}=\mathrm{z}_{2}=0\right)$, $\mathrm{x}$, $\mathrm{y}$ denote collocation point coordinates. In Fig. 3, the local coordinate system $(\xi$, $\zeta)$, aligned along the panel j, is visible, so is the collocation point $\mathrm{C}_{\mathrm{i}}$ (at panel middle). A nested loop is required to compute velocities induced at all collocation points by all panels, thus deriving a system of linear equations. The quantities $u_{p}$ and $v_{p}$ must be remapped back to the global coordinate system $(\mathrm{X}, \mathrm{Z})$ prior to computing the influence coefficient

$$
a_{i j}=(u, v)_{i j} \mathbf{n}_{i}
$$

which is essentially an element of left-hand side of the system equations. The latter quantity (free stream) is a dot product of free stream velocity and normal vector in global coordinate system

$$
R H S_{i}=-\left(U_{\infty}, V_{\infty}\right) \mathbf{n}_{i}
$$

which in turn belongs to the system right-hand side.

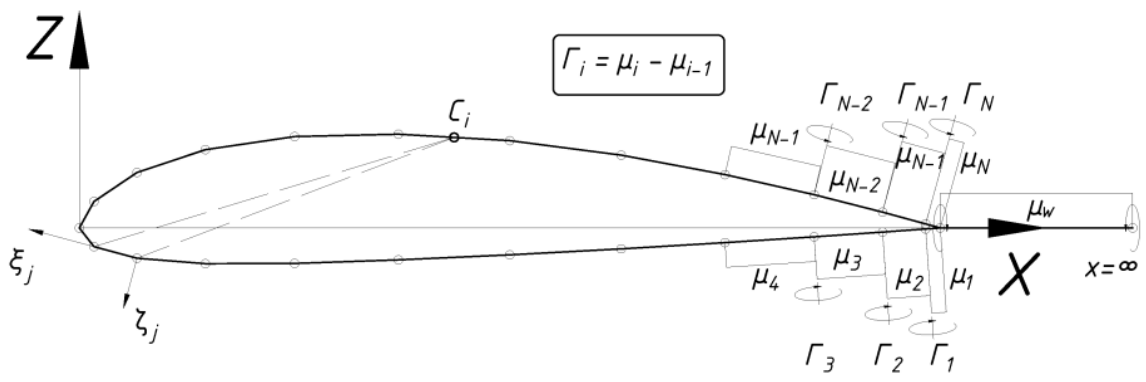

Fig. 3. Airfoil of Mugin 3, 15\% thickness, and wake panel, [2] 
After computing the aforementioned quantities, following linear nonhomogenous system of equations is obtained:

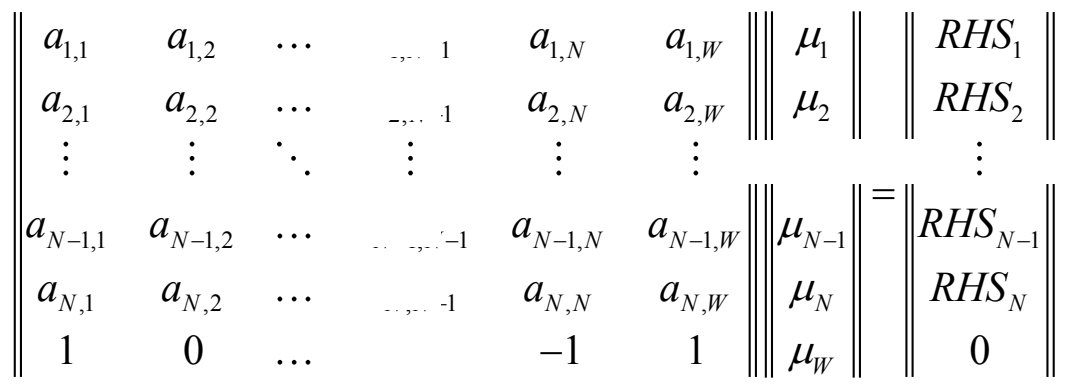

System (4) is augmented further by Kutta condition implying that circulation at the trailing edge should be zero. However, according to Fig. 3, the vortex strength at the trailing edge is found to be $-\Gamma=\mu_{1}-\mu_{N}$, [2], hence a wake panel is required to meet the condition requirements, i.e.

$$
\left(\mu_{1}-\mu_{N}\right)+\mu_{W}=0
$$

Equation (5) is added to the last row of system (4). In addition, a column is added to the matrix of coefficients denoting velocities generated by the wake panel (index $\mathrm{W})$ at the collocation point (index i). The system is said to be well defined and stable in terms of numerical solution, [2].

\section{Solving a linear algebraic system}

Having computed the influence coefficients, a non-homogenous linear algebraic system (4) is obtained in terms of doublet strength $\mu$ distribution along the airfoil contour. In the current study, a direct method of compact lower - upper (LU) factorization / decomposition of matrix A was employed to work out solution to the system (1). In general, there are three types of factorization thoroughly described in textbook [4]:

- Doolittle if U matrix has $1 \mathrm{~s}$ along its diagonal. In this case, the matrices elements might be solved for by means of following formulae:

$$
\begin{gathered}
u_{k j}=a_{k j}-\sum_{p=1}^{k-1} l_{k p} u_{p j}, \quad j=k, k+1, \ldots, n \\
l_{i k}=\frac{a_{i k}-\sum_{p=1}^{k-1} l_{i p} u_{p k}}{u_{k k}}, \quad j=k+1, \ldots, n
\end{gathered}
$$


- Crout if L matrix has $1 \mathrm{~s}$ along its diagonal. For the matrices elements at step $\mathrm{k}$ it follows:

$$
\begin{gathered}
l_{i k}=a_{i k}-\sum_{p=1}^{k-1} l_{i p} u_{p k}, \quad j=k, k+1, \ldots, n \\
u_{k j}=\frac{a_{k j}-\sum_{p=1}^{k-1} l_{k p} u_{p j}}{l_{k k}}, \quad j=k+1, \ldots, n
\end{gathered}
$$

(7)

- Cholesky if $\mathrm{U}=\mathrm{L}^{\mathrm{T}}$ or $\mathrm{L}=\mathrm{U}^{\mathrm{T}}$

(8)

$$
\begin{aligned}
& u_{k j}=\frac{a_{k j}-\sum_{p=1}^{k-1} l_{k p} u_{p j}}{l_{j j}}, \quad j=1,2, \ldots, k-1 \\
& u_{k k}=\sqrt{a_{k k}-\sum_{p=1}^{k-1} l_{k p}^{2}}
\end{aligned}
$$

The Cholesky decomposition is solely applicable to a Hermitian (self-adjoint), positive-definite matrix.

The basic concept of the LU decomposition is constructing lower and upper triangular matrices for the following equation to be true:

$$
A=L U \therefore L U \boldsymbol{\mu}=b
$$

The aforementioned decomposition might be used to solve for the unknown vector $\mathrm{U} \boldsymbol{\mu}=\mathbf{y}$ first, [5], i.e.

$$
A \boldsymbol{\mu}=L(U \boldsymbol{\mu})=L \mathbf{y}=b
$$

Then, the obtained intermediate vector $\mathbf{y}$ is to be used to solve for the vector $\boldsymbol{\mu}$

$$
U \boldsymbol{\mu}=\mathbf{y}
$$

The LU factorization is only possible if inverted matrix exists, i.e. $\operatorname{det}(\mathrm{A})=0$

$$
A^{-1}=\frac{1}{\operatorname{det}(A)} \operatorname{adj}(A)
$$




\section{Secondary quantities}

Having computed the doublet distribution along the airfoil, it is possible to work out values of some secondary quantities, [2], as follows:

- Perturbation tangential velocity in terms of induced velocities

$$
q_{t, i}=\sum_{j=1}^{N+1}(u, w)_{i, j} \mathbf{t}_{i}
$$

- Pressure coefficient

$$
C_{p, i}=1-\frac{\left(Q_{t \infty}+q_{t}\right)_{i}^{2}}{Q_{\infty}^{2}}
$$

In formula (14), $\mathrm{Q}_{\text {to }}$ stands for the dot product of free stream velocity and panel $\mathrm{i}$ unit tangent vector.

\section{Source code description and results validation}

The source code was built by Tiny C Compiler, [6]. In Fig. 4, the header file included in the solution might be seen. Apart from the function prototypes, an alias of a structure is defined. The structure contains main geometric quantities of a panel. These include pointers to dynamically allocated arrays containing panel end points, normal and tangent vectors, and collocation point. The header file also contains a function-like macro $\operatorname{IX}(i, j)$ taking row and column indexes $(i, j)$ as arguments. Throughout the source, one-dimensional arrays are solely used even in case of matrix of coefficients (left-hand side) of system (4).

Briefly, the software work sequence is following. An array of type myPanel is dynamically allocated containing as many panels as necessary (function void *malloc). All fields within a single panel are initialized by means of a text file containing airfoil panels coordinates. For the airfoil to be divided according to algorithm depicted in Fig 2, using a CAD software is recommended, for instance AutoCAD. Then the algorithm proceeds to computing each panel geometrical quantities, function geom(). The next step consists of two nested loops intended to compute velocities at current collocation point induced by current panel, function influenceDueToDoublet(). As it was mentioned earlier, the collocation point is placed at the panel center. Having computed the influence coefficients, a method of working out a solution to the non-homogenous linear system is invoked, function Doolittle(), Crout(). Eventually, results are exported to an stdout device and all allocated structures and arrays are freed, function free().

Broadly speaking, the header file shown in Fig. 4 is self-explanatory. 


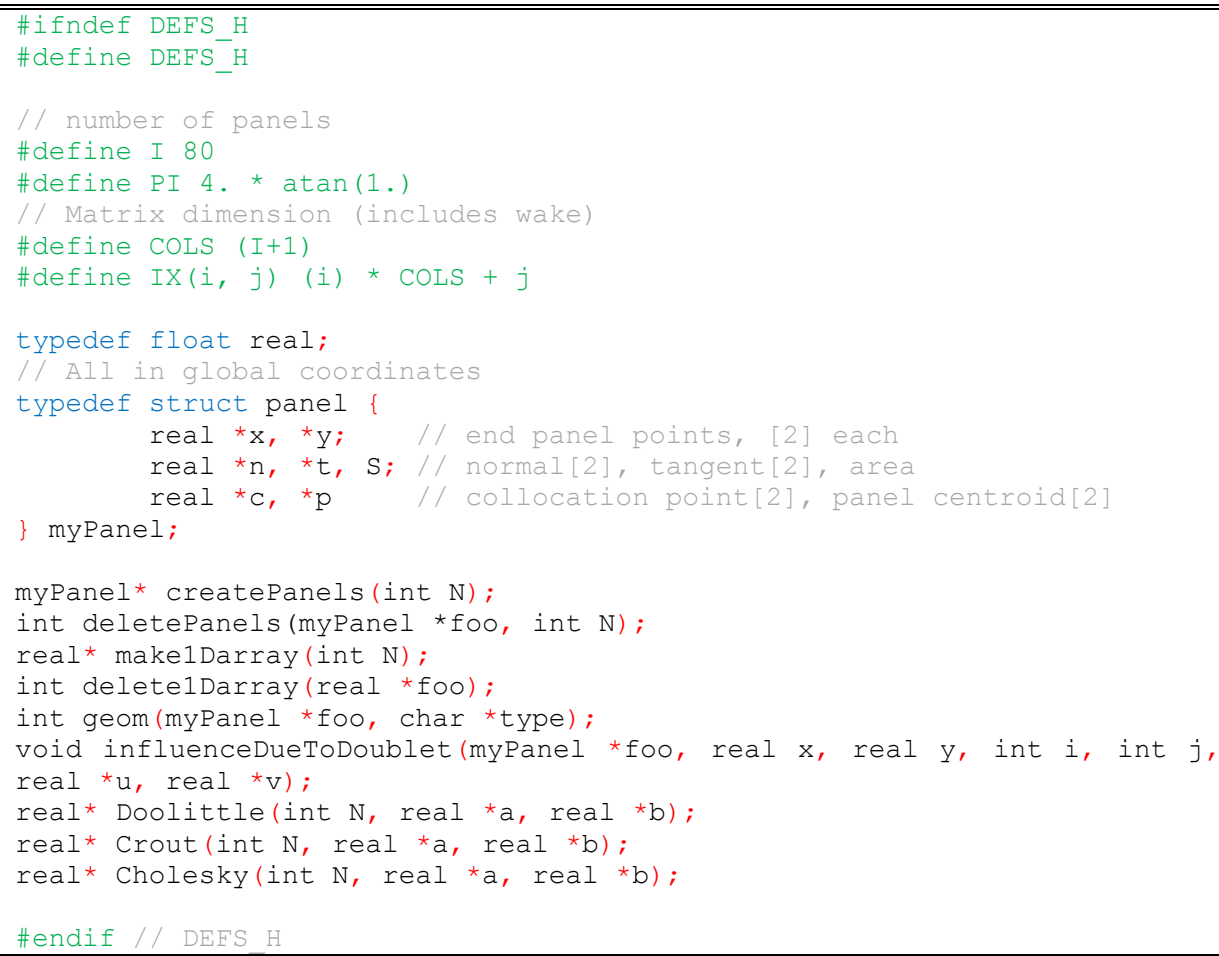

Fig. 4. A header file included in the developed software

In order to estimate the program ability to work out a solution in advance, a validation case was carried out about an ideal flow around a cylinder, 2D. The cylinder had been previously divided into 80 panels. It is widely known that the distribution of coefficient of pressure along the cylinder surface might be estimated according to following formula, [7]

$$
C_{p}=1-4 \sin ^{2} \theta
$$

where $\theta$ is a polar angle of which the coefficient $C_{p}$ in (15) is solely dependent. Formula (15) is derived from Bernoulli's equation for total energy conservation of ideal gas flow, i.e. in case of inviscid, incompressible, irrotational flow.

In Fig. 5, the solution of system (4), i.e. doublet distribution, is shown, so is the static pressure coefficient distribution, Fig. 6, computed by means of formula (14). For this particular test case, $\alpha=0 \mathrm{deg}, \mathrm{Q}_{\infty}=1$, cylinder diameter (chord) $=1$. Evidently, both numerical (14) and exact (15) solutions coincide, Fig. 6. The numerical solution does not include a zone of flow separation for an obvious reason, i.e. a boundary layer does not emerge in case of ideal gas flow. 


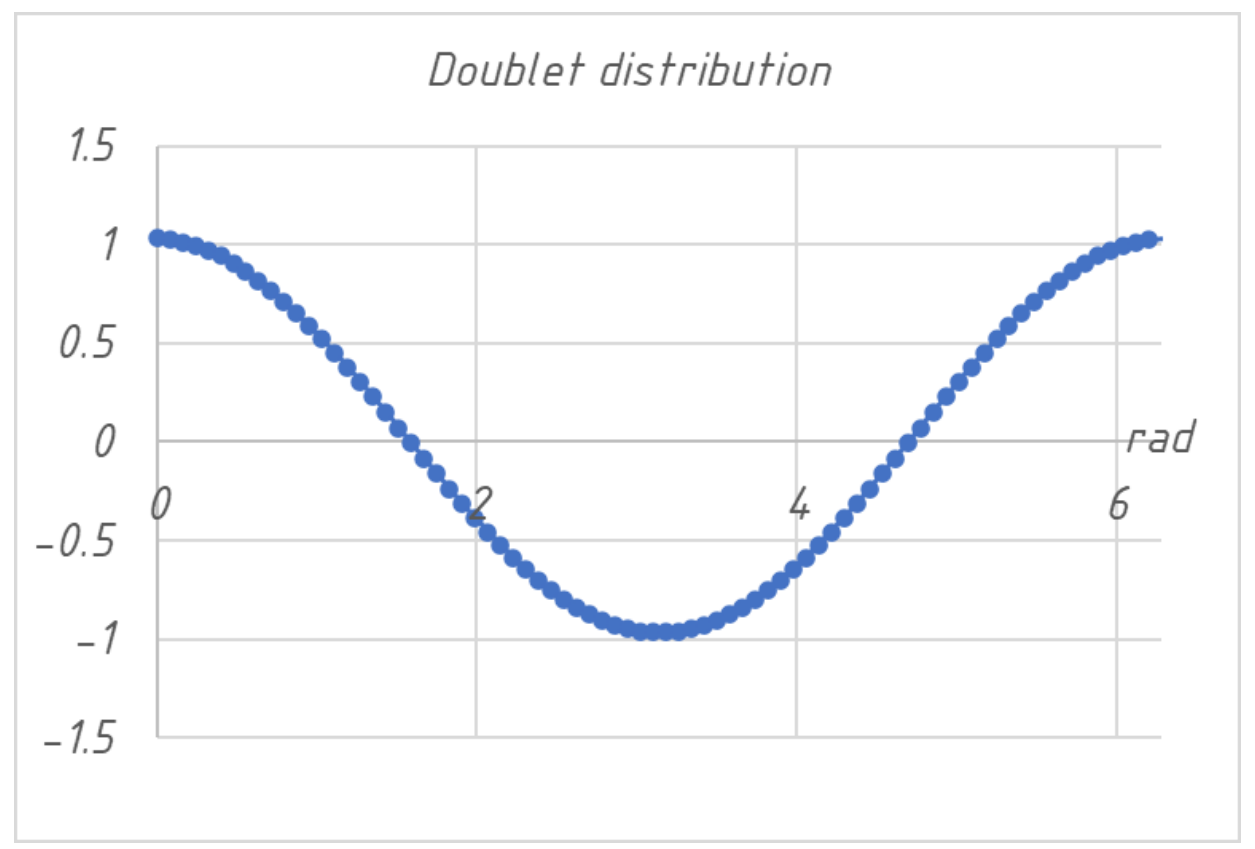

Fig. 5. Doublet distribution, circle, $\alpha=0 \mathrm{deg}, \mathrm{Re}=66177$

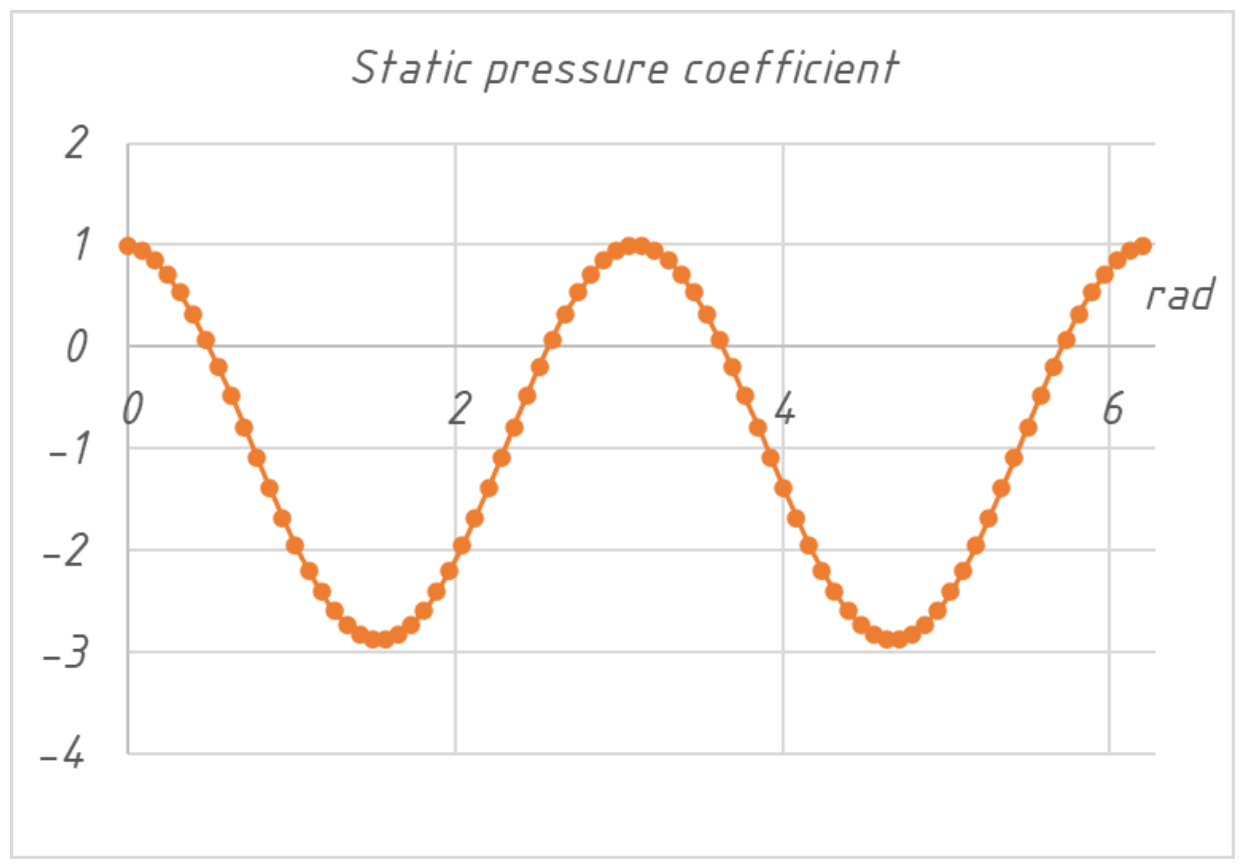

Fig. 6. Static pressure coefficient, circle, $\alpha=0$ deg, $R e=66177$ 


\section{Numerical results}

In Fig. 7, numerical solution of system (4) regarding Mugin wingfoil is shown. Test case details are outlined in the caption below the figure.

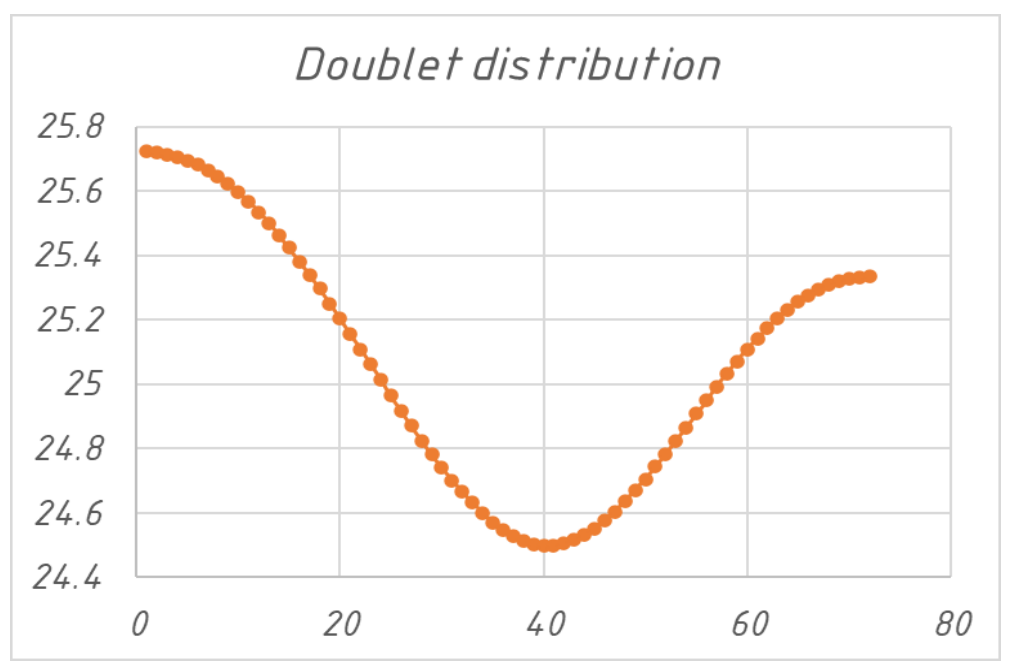

Fig. 7. Numerical solution of (4), Mugin 72 panels, Crout $L U, \alpha=10$ deg, $R e=66177$

In Fig. 8, the static pressure coefficient is shown regarding the same test case.

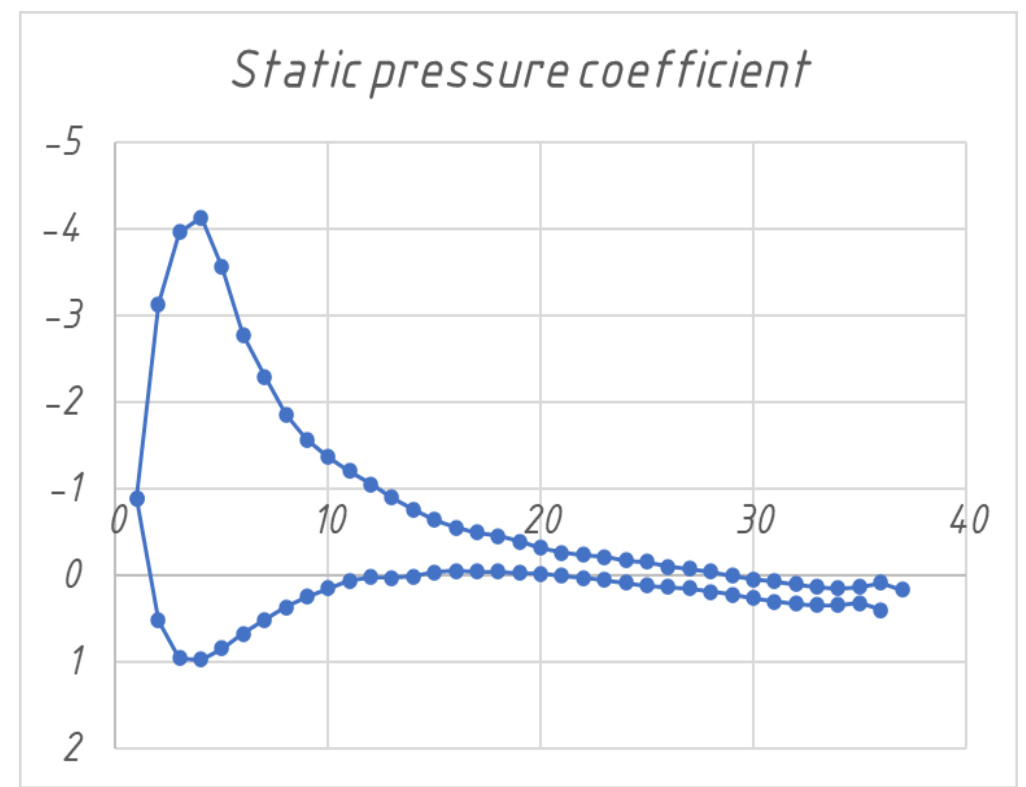

Fig. 8. Static pressure coefficient, Mugin 72 panels, $\alpha=10 \mathrm{deg}$, Re $=66177$ 


\section{Concluding notes}

Apart from static pressure coefficient, other secondary quantities might be computed, such as total lift and moment. Recalling the Kelvin's theorem, the total lift might be computed by taking the wake doublet strength, obtained after solving system (4). Bearing in mind small initial quantities $Q_{\infty}=1 \mathrm{~m} / \mathrm{s}, \rho=1.2 \mathrm{~kg} / \mathrm{m}^{3} \mu_{\mathrm{W}}=$ $-0.386 \mathrm{~m}^{2} / \mathrm{s}, 1=1 \mathrm{~m}$, then, following Joukowski theorem $\mathrm{L}=-\rho \mathrm{Q}_{\infty} \mu_{\mathrm{W}} 1=0.465 \mathrm{~N}$.

\section{References}

1. https://www.muginuav.com/product/new-mugin-3m-uav-v-tail-platform-frame-kit/

2. Katz, J., A. Plotkin, Low - Speed Aerodynamics, Cambridge University Press, NY, 2001, p.p. 283, 340, ISBN 978-0-521-66219-2, ISBN 978-0-521-66552-0

3. ARRAYPOLAR (Command), Autodesk@ Inc., Help file, 2020

4. Dahlquist, G., A. Bjorck, Numerical Methods, Dover Publications, 2003, p. 157, ISBN 0486-42807-9

5. Press, W., S. Teukolsky, W. Vetterling, B., Flannery, Numerical Recipes, The Art of Scientific Computing, Third edition, Cambridge University Press, 2007, ISBN-13 9780-521-88068-8, ISBN-10 0-521-88068-8

6. TCC. https://bellard.org/tcc/

7. Bertin, J., R. Cummings, Aerodynamics for Engineers, Sixth edition, Pearson Education Ltd., 2014, p.138, ISBN 10: 0-273-79327-6, ISBN 13: 978-0-273-79327-4

\section{ПРИЛОЖЕНИЕ НА МЕТОДА НА ДИСКРЕТНИТЕ ДИПОЛИ С ПОСТОЯНА ИНТЕНЗИВНОСТ ЗА АНАЛИЗ НА СТАЦИОНАРНО ТЕЧЕНИЕ ОКОЛО КРИЛЕН ПРОФИЛ}

\section{K. Методиев}

\section{Резюме}

В настоящата статия е приложен числен (панелен) метод за анализ на двумерно течение на идеален газ около крилен профил. Отначало профильт беше разделен на краен брой панели. Впоследствие панелите бяха заменени от диполи с постоянна интензивност. Добавен беше и панел (следа) към изходящия ръб на профила, за да се удовлетвори условието на Кута.

За да се реализира този алгоритьм, числена реализация беше разработена и компилирана на Tiny C Compiler. За да се реши числено получената линейна нехомогенна система уравнения, беше приложен директен метод на LU-декомпозиция на матрицата коефициенти, а именно Crout, Doolittle, Cholesky.

Получените резултати са валидирани с точно решение и показани за различни стойности на ьгъла на атака и числото на Рейнолдс. 